\title{
Pensar el dibujo CHARLA CON EMMANUEL PEÑA Leonardo Rodríguez*
}

〔 omo parte de un proyecto editorial del Comité de Artes, La Palabra y el Hombre quiso indagar en el mundo de la novela gráfica, el cómic y la ilustración e incluyó, en sus cuatro últimos números, dossiers de Nicolas de Crécy, Javier Arjona, Max Capdevila y Bef. Pensar el presente de esas técnicas, explorar su lenguaje, su saber y las posibles implicaciones que este tipo de "trabajos del arte" producen en la realidad eran los horizontes que guiaban nuestro designio. Durante el proceso, participamos en un evento sobre una de las relaciones culturales que últimamente más convoca en un mismo espacio-tiempo a ilustradores, novelistas gráficos y creadores del cómic: el mundo de la autopublicación. Fue allí donde, dibujando todo el tiempo, como si el germen de todo lo imaginario y su representación fueran los trazos, entramos en contacto con Emmanuel Peña. La charla que sostuvimos con él pretendió interrogar, mediante su trabajo, algunas ideas desde las cuales se puede pensar el dibujo.

\section{$* * *$}

Leonardo Rodríguez: ¿Cuántos años llevas dibujando?

Emmanuel Peña: Dibujo, como muchos, desde que tuve mi primera cubeta llena de crayolas, y no dejé de hacerlo por ningún motivo; en algún momento incluso se volvió necesario, y fue parecido a un salvavidas para mí: cuando en mi infancia padecí principios de epilepsia y perdí habilidades motrices, fue el dibujo lo que me llevó de regreso al juego. Más tarde, cuando tocó ser adolescente, el dibujo me dejó encontrar el camino; incluso cuando llegué a vivir a la CDMX y no tenía amigos y me abrumaba ir a la calle, también estuvo conmigo. Más allá de lo predecible o lo que uno puede planear, se volvió uno de los ejes centrales de mi oficio de diseñador gráfico y el mejor inicio de cada proyecto.

LR: ¿Recuerdas cuál fue el primer dibujo que te provocó emoción?
EP: Un primer dibujo que pudo sorprenderme, creo, fue uno muy sencillo: la historia del niño que no quería estudiar y se convirtió en un burro; pero mucho tiempo después, un día llegó a mis manos un libro loquísimo que se llama Elvis Road, el cual me movió los esquemas de lo que significaba hacer un dibujo y qué tan loco podía ser. Éste inspiró mucho mis primeros libros personales.

LR: ¿Cómo se mira el mundo a través del dibujo?

EP: No lo sé, tal vez tendría que tener un dispositivo muy moderno y aprender a utilizarlo. Pero desde el desconocimiento puedo decir que el dibujo no tecnológico sigue estando aparte de lo moderno, realmente no hay manera de emular esa experiencia.

El papel siempre será papel y la tinta, siempre tinta; existe una cualidad de inmediatez inigualable, y es el tiempo mismo el que le va sumando y restando atributos al dibujo; pero creo, sobre todo, que el dibujo juega lejos de lo digital porque puede conservar la posibilidad del error. La manera de equivocarse trabajando con papel es, para mí, de las cosas más valiosas que tiene el acto de dibujar. De otro modo no sería comprensible la potencia y perfección del trabajo de los grandes dibujantes. Cuando enfrentamos una hoja en blanco, sí tenemos nuestras formas de abordarla, nuestros caminos fáciles, y esta zona de comodidad, a mi parecer, es posible romperla trabajando en papel, lo que llaman soltar la mano. Pienso también que la opción digital tendría que ver más con buscar darle salida a un dibujo que va a ser impreso o funcionará para algo en específico, y el dibujo no tiene estrictamente esa función. El dibujo existe antes de pensar en ocupar una técnica.

LR: $¿$ Crees que hay un lenguaje o pensamiento del dibujo?

EP: $¡$ Híjole!, es una pregunta con muchas posibles respuestas. El dibujo existe tal como lo conocemos en concepto y posibilidades, y son otras disciplinas las

${ }^{*}$ Coordinador de las secciones Arte y Dossier de La Palabra y el Hombre. 
que retoman cualquier elemento. Pero digamos que el dibujo y cualquier código de lenguaje o atributo que se le mire es previo a otras disciplinas. Entonces, puedo pensar que tiene la particularidad de ser un canal único y diferente a todo, en el que podemos mirar la realidad y volverla trazos en un papel. Esta pregunta plantea algo extraño: suena a querer saber si el dibujo tiene algo genuino y creo que sí lo tiene, pues son sus límites y su forma los que lo determinan. El lenguaje o pensamiento específico es tan variado y complejo como el hecho de que cada persona que sujeta un lápiz con la mano, lo hace partiendo de que su cabeza y su historia de vida son ya muy complejas, genuinas e irrepetibles; creo que esto nos hace pensar que el dibujo es un canal de comunicación único.

LR: En algún lado leí que el libro digital no había triunfado del todo como industria porque no lograba replicar las relaciones que el libro como objeto producía y sigue produciendo; me refiero a las visitas al café, a las librerías o la simple relación de los lectores con el papel, la tinta y el espacio que se le dedicaba a cada buen libro en casa. En este sentido, sigo observando múltiples situaciones que el dibujo convoca, donde el lápiz y el papel siguen siendo el utensilio del acontecimiento. ¿Qué tiene el dibujo que parece ser una actividad que se ha resistido a la tecnología? ¿Crees que sea cierto?

EP: Pienso que en el mundo de los ilustradores o de la gente creativa en general, cada vez se dibuja menos; tal vez tendrías que preguntarle a un pintor para saber lo que piensa sobre la relación entre historia del dibujo y actualidad del arte, pero puedo imaginar que la respuesta sería poco alentadora. Desde mi disciplina, veo que es poco lo que se hace de dibujo; hay ilustradores que sólo dibujan para entregar una imagen y que incluso lo hacen saltándose la etapa del boceto; también hay otros que al parecer síllenan las libretas, aunque no sabría si en todos los casos es un acto de búsqueda o simplemente tratan de emular lo que está chido. Pienso que en este momento histórico todo lo que hemos visto previamente, sumado a las posibilidades de los multimedia, deja al dibujo en una posición muy vulnerable.

LR: ¿Crees que el dibujo tiene alguna potencia?

EP: Lo mencionaba en otra respuesta. El error, los errores no se planean, o por lo menos no por completo; el error es lo que vuelve genuino, lo que permite la posibilidad de que algo tenga intensidad propia. Hace unos días vi un cuaderno de dibujo que se convertirá en libro; aparentemente tenía ejercicios sobre distintas formas de arrastrar un carbón en la página. Mi primera reacción fue pesimista; esto parece demasiado sencillo y vano, pero después pensé en el pánico que daría voltear cada página y hacer los siguientes trazos, por la no-posibilidad de borrar. Ahí estaba el verdadero espíritu de ese cuaderno: el error, tener que seguir dibujando, pero intentando conservar ese estado de ánimo y cometer los suficientes errores o aciertos en cada página para que todo tuviera el mismo discurso.

LR: ¿Cómo crees que sea el tipo de sujeto que produce el dibujo?

EP: Pienso que se trata de alguien con infinita curiosidad, que mira atento siempre, que tiene una gran capacidad de reflexión; pero de entre los tipos de personajes que puedan existir, los que me parecen más interesantes son los que están en una verdadera búsqueda de la forma, los que decidieron no dibujar de una manera específica y repetir la fórmula. $\mathrm{Me}$ viene a la mente el caso de un par de ilustradores: Juan Palomino y Armando Fonseca, que tienen un trabajo muy bello y están teniendo mucho éxito en el mundo editorial de los libros para niños y jóvenes. Ellos son filósofos de formación, pero se dedican a ilustrar; creo que es una combinación de formas muy interesante para abordar las ideas, porque justo dibujar trata de volvernos un filtro de lo que entra por nuestros ojos y sale por nuestras manos. Ellos, con su capacidad reflexiva y su manera de ver el mundo, han sido capaces de construir un imaginario poderoso. Peña?

LR: ¿Hacia dónde va el dibujo de Emmanuel

EP: Creo que no tiene un camino definido: si miro hacia atrás, a los inicios, veo la intención de querer parecerme a todo lo que me gusta de otros dibujantes; si miro más cerca, al presente, parece que quiero seguir dibujando cosas urbanas porque siento que es un tema muy complejo y difícil de agotar. Pero si un día dejo de vivir en la CDMX, estoy seguro de que serán otros temas los que me llamarán la atención. Podría decir que la constante será que quiero dibujar lo que me parezca cercano e interesante. Ahora trabajo todo el tiempo con lápiz, pero me gustaría hacerlo directamente con tinta, perderle por completo el miedo al error y más bien aprovecharme de éste. LPyH

\footnotetext{
- Emmanuel Peña (Tula, 1987) es diseñador gráfico e ilustrador. Sus verdaderos oficios son pasear en bicicleta y dibujar. Ha publicado algunos libros, así como diseñado e ilustrado varios otros. En 2016 fue residente de la Casa de los Autores en Angulema, Francia, y un año después, ganador del segundo lugar del Premio de Novela Gráfica Ciudades Iberoamericanas. Actualmente es profesor en la Universidad Centro y está por publicar su segunda novela gráfica, Color de hormiga.
} 